\title{
Glyceraldehyde-3-Phosphate Dehydrogenase
}

National Cancer Institute

\section{Source}

National Cancer Institute. Glyceraldehyde-3-Phosphate Dehydrogenase. NCI Thesaurus.

Code C104411.

Glyceraldehyde-3-phosphate dehydrogenase (335 aa, $\sim 36 \mathrm{kDa}$ ) is encoded by the human GAPDH gene. This protein is involved in carbohydrate metabolism. 